\title{
Zinc Deposition During ESI-MS Analysis of Peptide-Zinc Complexes
}

\author{
Haritha Mattapalli, William B. Monteith, Colin S. Burns, and \\ Allison S. Danell \\ Department of Chemistry, East Carolina University, Greenville, North Carolina, USA
}

\begin{abstract}
Electrospray ionization (ESI) mass spectrometry (MS) has proven to be an extremely powerful technique for studying the stoichiometry and binding strength of peptide-metal complexes. We have found a significant new problem in the ESI-MS of zinc-peptide systems involving the deposition of zinc in the ESI emitter. This deposition of zinc during the experiment removes a significant amount of zinc ions from the solution, impacting the resulting mass spectral intensities used to quantify the amount of the zinc-bound species. Analysis of infused zinc-peptide samples with atomic absorption spectrometry and with a custom-built nanoflow ESI source confirms the alteration of the analyte solutions with positive or negative or no potential applied to the emitter. Ultimately, the location of the zinc deposition was determined to be the stainless steel emitter. The use of a custom-built nanoESI interface using glass emitters was found to mitigate the zinc deposition problem. The phenomenon of metal deposition warrants further investigation as it may not be limited to just zinc and may represent a significant obstacle in the ESI-MS analysis of all protein-metal systems. (J Am Soc Mass Spectrom 2009, 20, 2199-2205) @ 2009 American Society for Mass Spectrometry
\end{abstract}

$\mathrm{T}$ here is wide interest across disciplines in characterizing the structure and function of metal-binding biomolecules. Although not all systems are amenable to study by a single technique, mass spectrometry has been recognized as a powerful method for determining the stoichiometry and binding strength of metalpeptide or metal-protein complexes [1,2]. This is especially true for spectroscopically silent (d10) metal ions such as $\mathrm{Zn}^{2+}$ and $\mathrm{Cd}^{2+}$ [3-8]. Many important samplerelated and instrumental factors must be considered when making these types of measurements. Careful selection of standardized reagents and characterization of the concentrations of resulting solutions are necessary when quantitative work is to be performed [9]. Specific mass spectrometric considerations such as the ionization and transfer efficiencies of apo and holo peptides must be considered [2]. Arguably, one of the most important issues is considering oxidation and reduction activity during sample preparation and ionization. Rigorous control of $\mathrm{pH}$, temperature, and exposure to air is required. Anticipating or preventing compensatory electrolytic deposition of metal ions (reduction in negative mode ESI and oxidation in positive) as well as oxidation of residues such as cysteine during positive ESI is crucial [10-14].

We have found a significant new problem in the ESI process of zinc-peptide systems that may contribute to discrepancies in the mass spectral intensities used to

Address reprint requests to Professor A. S. Danell, Department of Chemistry, East Carolina University, 300 Science and Technology Building, Greenville, NC 27858, USA. E-mail: danella@ecu.edu quantify the amount of the zinc-bound species present in a sample. In turn, these data could not be reliably used for reporting dissociation constants $\left(\mathrm{K}_{\mathrm{d}}\right)$ measured with mass spectrometry. We have observed, under a variety of conditions, carryover of zinc from one experiment to the next. Thorough cleaning with mildly acidic solution certainly solves the intermediate carryover problem between sample analyses. However, we have measured significant changes in relative zinc content in solution before and after short (minutes) ESI-MS experiments. This observation indicates a measurable amount of zinc is lost from solution during the mass spectrometry experiment, which alters the mass spectral data used to determine features of the zincpeptide complex. We performed several experiments to investigate this phenomenon further, and have learned zinc loss occurs regardless of the ESI polarity used or the binding strength of the peptide. We also investigated the effect of infusion rate on the amount of zinc lost from solution, and will present the use of nanoESI as both a characterization method and, potentially, a method to solve this problem.

\section{Experimental}

Experiments were performed on Bruker EsquireLC and Bruker Esquire 3000plus Quadrupole Ion Trap Mass Spectrometers (Bruker Daltonics, Billerica, MA). The same ESI emitter assembly, shown in Figure 1, was used on both instruments. Sample was infused with a KD Scientific syringe pump at $0.250 \mathrm{~mL} / \mathrm{h}$ unless otherwise noted. Sample is introduced with a $250 \mu \mathrm{L}$ Hamilton no. 


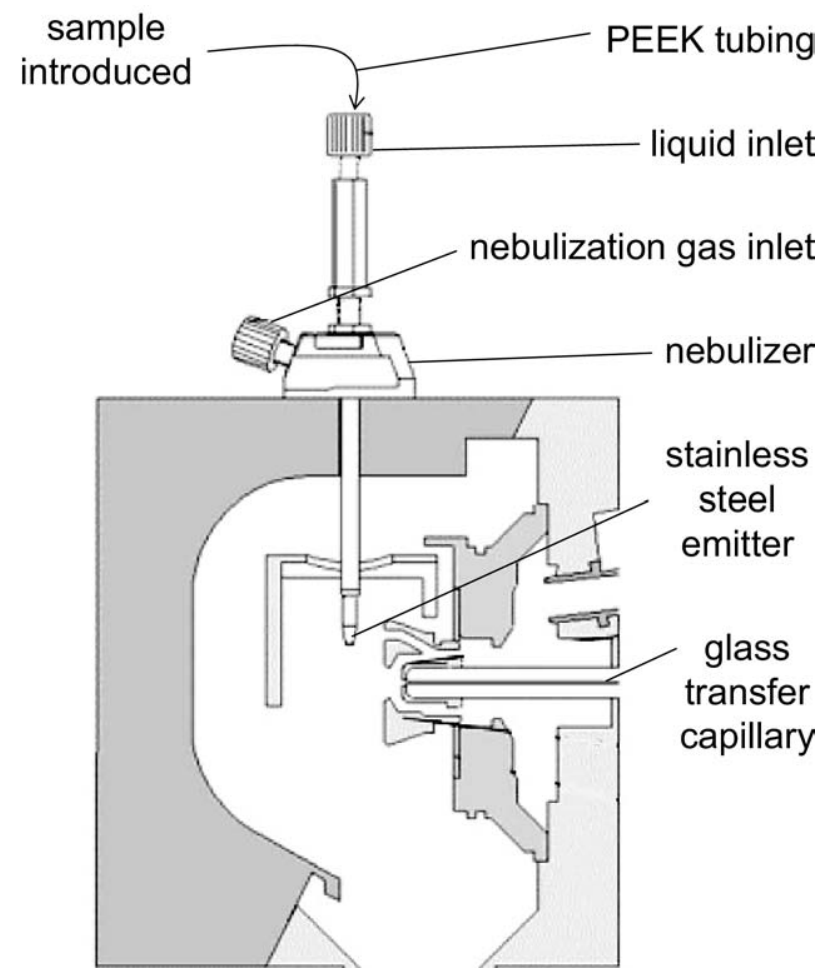

Figure 1. Schematic of the electrospray ionization source. See the Experimental section for more detail.

1725 gas-tight syringe equipped with a no. 22 gauge needle into a Rheodyne needle port lined with a Teflon liner tube. The port is connected to $\sim 75 \mathrm{~cm}$ of $0.005 \mathrm{in}$. i.d. polyetheretherketone (PEEK) tubing via a 1/16 in. zero dead volume union. Another union is used to connect the other end of the PEEK tubing to the liquid inlet shown in Figure 1. Inside the electrospray nebulizer sits the ESI emitter, constructed of stainless steel (approximately $9 \mathrm{~cm}$ long; $0.10 \mathrm{~mm}$ i.d., $0.17 \mathrm{~mm}$ o.d. at tapered end). This ESI assembly was originally sold with the Esquire 3000plus mass spectrometer but is also available separately (part no. G1946; Agilent Technologies, Wilmington, DE). Sample travels from the syringe, through PEEK tubing, and then the stainless steel emitter. It is sampled off-axis into the glass transfer capillary shown in Figure 1.

The nanoESI source was constructed in-house. The nanoESI emitters are constructed from borosilicate glass capillaries $(0.58 \mathrm{~mm}$ i.d., $1.0 \mathrm{~mm}$ o.d.), which are drawn to a fine tip (5-10 $\mu \mathrm{m}$ i.d.) with a Sutter P-97 Flaming/ Brown micropipette puller (Novato, CA). The nanoESI emitter is directed at the aperture of the glass transfer capillary. Since the nanoESI emitters are not metallized, a platinum wire $(0.10 \mathrm{~mm}$ diameter; Sigma Aldrich, St. Louis, MO) is inserted into the open end of the emitter to provide electrical contact to ground the solution in the emitter. For both ESI and nanoESI sources, the emitter is grounded and the spray potential is applied to the counterelectrode at the opening of the source. The electric potential used to initiate ESI was 3.5 to $4.0 \mathrm{kV}$, and 700 to $1000 \mathrm{~V}$ for nanoESI. The source conditions were optimized to minimize fragmentation. The most important parameter in this optimization was the setting of the capillary exit-skimmer potential difference to $126 \mathrm{~V}$. The dry gas flow was $5 \mathrm{~L} / \mathrm{min}$ at $250{ }^{\circ} \mathrm{C}$ for ESI and $1 \mathrm{~L} / \mathrm{min}$ at $30^{\circ} \mathrm{C}$ for nanoESI, and the nebulizer gas pressure was 10 psi for ESI, but was not used for nanoESI.

Flame atomic absorption spectrophotometry experiments were performed on a Perkin Elmer AAnalyst 200 (Waltham, MA). The $213.86 \mathrm{~nm}$ line of a zinc hollow cathode lamp was used as the source, and background subtraction was performed. A spacer typically inserted before the impact bead in the nebulizer was removed to increase sensitivity. The limit of detection for zinc in this mode of operation is $\sim 0.10 \mu \mathrm{M}$, and the response is linear to $12 \mu \mathrm{M}$. Before analysis, $20 \mu \mathrm{L}$ of $6 \mathrm{~N}$ nitric acid was added to the original $500 \mu \mathrm{L}$ aliquots of peptide: metal sample, which were then diluted to $5.0 \mathrm{~mL}$. The nitric acid was added to sample solutions to release any zinc bound to peptide so that elemental zinc could be introduced in the atomic spectrometer.

The putative zinc binding region of the protein prothymosin- $\alpha$, Ac-WEVD(E) ${ }_{5} \mathrm{GG}(\mathrm{E})_{8}$ GDGEEEDGDEDEEAESATGKR-NH ${ }_{2}$ (ProT $\alpha(50-89)$ N50W, hereafter called ProT $\alpha$ ) was synthesized and purified as previously described [15]. The zinc finger (Cys4) peptide, KLCEGGCGGCGGCGGW-NH ${ }_{2}$, was obtained from Biopeptide (San Diego, CA), and the phytochelatin (PC4) with the sequence $(\gamma \mathrm{EC})_{4}-\mathrm{G}$ was obtained from Anaspec (San Jose, CA). Both purchased peptides were purified by the manufacturer and used directly.

Sample solutions were prepared at 5 to $10 \mu \mathrm{M}$ peptide concentrations in 10/90 ( $\mathrm{vol} / \mathrm{vol}$ ) methanol/water buffered to $\mathrm{pH} \sim 7$ with $2 \mathrm{mM}$ N-ethylmorpholine for ProT $\alpha$ or 20-25 mM ammonium acetate for the other peptides. Concentrations of peptides containing tryptophan residues, ProT $\alpha$, and Cys4 were determined using UV spectrophotometry at $280 \mathrm{~nm}$. Molar equivalents of zinc chloride (99.6\%, ACS Certified Reagent; Fisher Scientific, Fair Lawn, NJ) were added at varied amounts, as stated in the text, and solutions were heated to $50{ }^{\circ} \mathrm{C}$, shaken for $1 \mathrm{~h}$, and then centrifuged before MS analysis.

\section{Results/Discussion}

We have analyzed several zinc-binding peptides using ESI-MS, and the same carryover of zinc metal in the source was observed for all species studied. One of the systems examined is a zinc finger peptide called Cys4, which strongly binds one zinc ion at $\mathrm{pH} 7\left(\mathrm{~K}_{\mathrm{d}} 8.0 \mathrm{pM}\right)$ [16]. Contamination of the source with zinc was observed when a solution of only the Cys4 peptide was infused, but the Cys4: $\mathrm{Zn}^{2+}$ complex was detected. First, using positive mode ESI, a "clean" spectrum of $5 \mu \mathrm{M}$ Cys4 was obtained, as shown in Figure 2a. Singly- and doubly-charged Cys4 ions appear, as well as low intensity peaks related to the buffered solvent system below $m / z$ 500. No significant fragment ions were detected, 


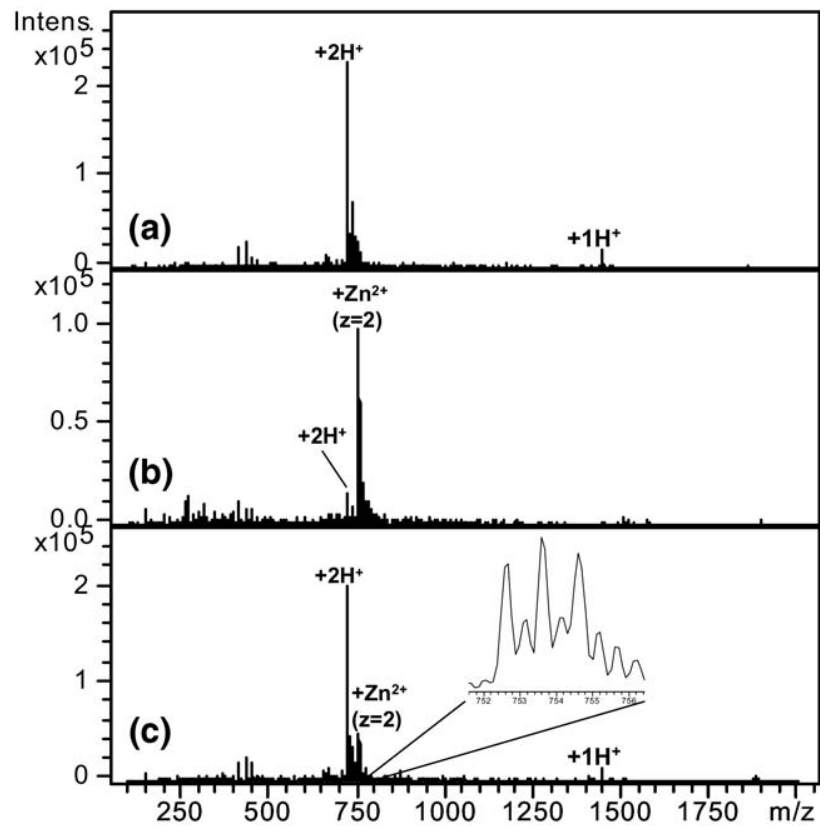

Figure 2. Mass spectra of (a) $10 \mu \mathrm{M}$ Cys4, (b) 1:2 (10 $\mu \mathrm{M}$ and 20 $\mu \mathrm{M})$ Cys4:Zn ${ }^{2+}$, and (c) $10 \mu \mathrm{M}$ Cys4 after infusing the solution used to obtain the spectrum in (b). The $(\mathrm{M}+\mathrm{Zn})^{2+}$ isotopic distribution is magnified in panel (c).

indicating the source conditions were sufficiently gentle to work with noncovalent complexes. Zinc was introduced by infusing a solution of $5 \mu \mathrm{M}$ Cys4 and $10 \mu \mathrm{M}$ $\mathrm{Zn}^{2+}\left(1: 2 \mathrm{Cys} 4: \mathrm{Zn}^{2+}\right)$, and any precipitated zinc was centrifuged out of this solution before infusion. A representative spectrum is shown in Figure $2 \mathrm{~b}$. This solution was infused for approximately $5 \mathrm{~min}$ at 0.250 $\mathrm{mL} / \mathrm{h}$, which corresponds to introducing about $21 \mu \mathrm{L}$ of solution, or about $10 \mathrm{nmol}$ of Cys4 and $20 \mathrm{nmol} \mathrm{Zn^{2+ }}$. The percent of peptide signal found in the zinc-bound form can be calculated from the intensities of the Cys4 and Cys4: $\mathrm{Zn}^{2+}$ signals in the mass spectrum, using eq 1 :

$$
\frac{I_{C y s 4: \mathrm{Zn}^{2+}}}{I_{C y s 4}+I_{C y s 4: \mathrm{Zn}^{2+}}} \times 100
$$

At 2.0 M equivalents of zinc added to the solution, we would expect to measure $100 \%$ of the peptide signal in the Cys4: $\mathrm{Zn}^{2+}$ state. Figure $2 \mathrm{~b}$ shows that $87 \%$ of the peptide was detected bound to $\mathrm{Zn}^{2+}$.

After electrospraying the 1:2 Cys4: $\mathrm{Zn}^{2+}$ solution, the syringe, transfer line, and stainless steel emitter were cleaned with $750 \mu \mathrm{L}$ (three $250 \mu \mathrm{L}$ syringefuls) of water, our typical cleaning protocol. Although a dilute acid solution was incorporated at a later point to better rid the source of any leftover metal, at this point in the experiments a simple aqueous flush was used. Since the total volume of solution occupying the transfer/infusion lines is under $10 \mu \mathrm{L}$, using over 75 times this volume in water to flush the lines was thought to be a reasonable protocol. But it was under these cleaning conditions that we realized that a significant amount of zinc from the previous solution was being left behind somewhere in the ESI source. This was detected when a solution containing only $5 \mu \mathrm{M}$ Cys 4 was infused, but peaks corresponding to the +1 and +2 charge states of Cys4: $\mathrm{Zn}^{2+}$ persisted in the mass spectra for $>40 \mathrm{~min}$, slowly decreasing with time. Figure $2 \mathrm{c}$ shows a representative mass spectrum acquired during that period (about 8 min after initiating the spray), when $27 \%$ of the peptide was detected bound to $\mathrm{Zn}^{2+}$. The initial appearance and then decline in Cys4: $\mathrm{Zn}^{2+}$ signal indicates that zinc was being introduced to the apo-peptide solution during analysis, and that the zinc supply was being depleted over time.

We were initially tempted to attribute our zinc carryover problems to uncontrolled redox processes. Redox active metals are known to electrolytically deposit to compensate for charge imbalance during the ESI process [11, 17-20]. But because so much high quality work has been done over the last ten years in understanding the redox processes, which can occur during ESI of solutions containing redox active metal ions, peptide ions, or both, several observations from our experiments can be used to rule out redox phenomena as a cause. First, positive mode ESI was used for infusing both the Cys4: $\mathrm{Zn}^{2+}$ and Cys4 solutions. Zinc should remain in the $\mathrm{Zn}^{2+}$ oxidation state during positive mode ESI, so it should not electrolytically deposit. In fact, ESI emitters constructed of zinc have been used to show that compensatory oxidation of the zinc to $\mathrm{Zn}^{2+}$ occurs in positive mode ESI [21]. Second, the polarity of the ESI potential was not changed at any point during this sequence of experiments, which would be a requirement for releasing electrolytically deposited metals. Consequently, we began to suspect we were observing a surface effect somewhere along the line in our source or mass spectrometer, and thus began methodically switching out parts from another instrument that was not used for metal analysis. Specifically, it was suspected that the PEEK transfer lines, the electrospray needle, or the glass transfer capillary (see Figure 1) could have been the site where some sort of deposition of $\mathrm{Zn}^{2+}$ was occurring. Thus, we again monitored for zinc carryover from previously infused Cys4: $\mathrm{Zn}^{2+}$ solutions. This was achieved by flushing the system with copious amounts of water followed by Cys4, and the Cys4: $\mathrm{Zn}^{2+}$ signal was still observed. These experiments were performed using each of the "clean" components individually substituted into the instrument during the Cys4 infusion. While an excess of $\mathrm{Zn}^{2+}$ was used to generate Figure 2, during the subsequent experiments the deposition was observed when equivalent or even substoichiometric amounts of metal were used. Ultimately, the location of the zinc deposition was determined to be the stainless steel emitter, because Cys4: $: \mathrm{n}^{2+}$ signal was not observed when a "clean" Agilent nebulizer assembly was installed.

We do not attribute the observed behavior to reduction of the $\mathrm{Zn}^{2+}$ ion because of the oxidizing conditions of positive mode ESI. However, we could not rule out 
any influence the ESI polarity may have on the process unless we worked under reducing conditions as well. Since Cys4 is amenable to negative mode ESI as well, we were able to reproduce the same carryover of zinc when analogous negative polarity experiments were conducted (data not shown). Thus, the phenomenon is independent of polarity, although from these experiments we could not determine whether the spray potential itself played a role, or whether the Cys4 peptide sequence or binding affinity influenced the process.

An offline quantitative analysis scheme was devised to measure the zinc content of solutions before and after infusion through the source assembly, in the absence of applied ESI potential. This approach allows us to determine if the ESI potential is in fact necessary to observe this phenomenon. If the ESI potential is not required, AAS provides a straightforward method to simply determine what percentage of zinc originally dissolved in an analyte solution is removed during infusion through the ESI source, without requiring ionization and vaporization of the analyte. Five hundred $\mu \mathrm{L}$ aliquots of $10 \mu \mathrm{M}$ Cys 4 and $10 \mu \mathrm{M} \mathrm{Zn}^{2+}\left(1: 1 \mathrm{Cys} 4: \mathrm{Zn}^{2+}\right)$ were infused at several different flow rates in positive ESI mode: $0.250,1.00$, and $2.00 \mathrm{~mL} / \mathrm{h}$. Because no nebulizing gas or ESI potential was used to generate electrospray, the solutions slowly dripped out of the emitter into a plastic collection vial, which was surrounding the emitter exit to avoid any sample loss. Between infusions, the stainless steel emitter was cleaned with $250 \mu \mathrm{L} 2 \%$ acetic acid and $2.5 \mathrm{~mL} 0.5 \%$ acetic acid to rid it of zinc. (It was found that the acidic wash was more effective in ridding the emitter of zinc than the use of a chelator such as EDTA.) Then, the emitter was flushed with $7.5 \mathrm{~mL}$ water or until the $\mathrm{pH}$ of the solution exiting the emitter did not deviate from $\mathrm{pH}$ 7. The removal of zinc was evidenced by the acquisition of a "clean" Cys4 spectrum containing no zinc.

Original (uninfused) and infused samples were treated as analyte solutions so that the relative drop in zinc concentration from the original and infused samples could be conveyed. The AAS results (Figure 3) show that the zinc concentration of a solution drops after it has been infused. Thus, the ESI potential does not have to be applied for zinc deposition in the ESI emitter to occur. The AAS results corroborate the ESI-MS results: AAS shows zinc is "lost" from solution after infusion, and ESI-MS results indicate that the lost zinc is reintroduced to newly infused solution. Additionally, Figure 3 shows that the drop in zinc concentration from the original to the infused samples was highest at $0.250 \mathrm{~mL} / \mathrm{h}$, which is the flow rate closest to what is typically used in this source $(0.100-0.250 \mathrm{~mL} /$ h). Less zinc was lost as the flow rate increased, indicating that the timescale of deposition requires slower flow or that the fast flowing fluid quickly reincorporates the deposited zinc. The most important finding is that a significant amount of zinc is lost from the original sample during its travel through the emitter

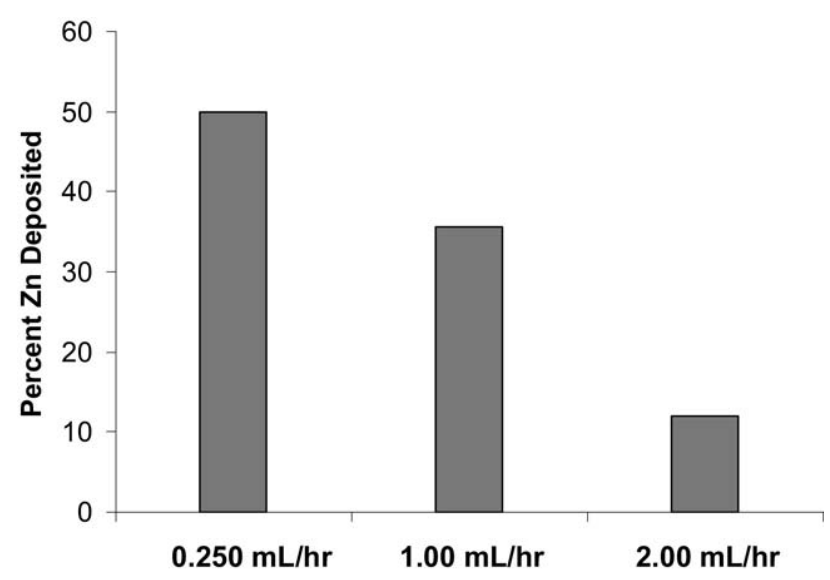

Figure 3. Effect of flow rate on the amount of zinc deposited in the ESI emitter. AAS was used to determine the relative drop in zinc concentration in the $10 \mu \mathrm{M}$ Cys $4: \mathrm{Zn}^{2+}$ solution before and after positive mode ESI.

at typically used flow rates, even when the zinc is initially bound to a very strong zinc binder like Cys4.

As mentioned above, zinc deposition needed to be detected with another peptide sequence to confirm this phenomenon was not somehow unique to the Cys4 sequence. We have worked extensively with the 40 amino acid putative zinc binding region of prothymosin- $\alpha$, $(\operatorname{ProT} \alpha)$. This highly acidic, natively unfolded peptide has been shown to adopt an ordered structure upon zinc binding, but it does not contain any residues traditionally involved in zinc-binding such as cysteine, histidine, or methionine [22, 23]. ProT $\alpha$ weakly binds as many as five zinc ions at $\mathrm{pH} 7$ [24]. To date, a reproducible set of $\mathrm{K}_{\mathrm{d}}$ values for the zinc-binding events has not been established, so this work cannot be used to compare current data with previously observed results. In addition, the difficulty of synthesizing and preparing this particular peptide for mass spectral analysis has been the subject of a previous publication, hence the different solution conditions (e.g., different buffer) used for this peptide versus the Cys4 [24]. However, this system does provide a way to rule out redox processes involving the peptide as a contributing cause for zinc loss and deposition. Redox chemistry must be considered when working with thiolcontaining peptides such as Cys4, which, in the apo-form, can oxidize to form disulfide bridges.

Several experiments analogous to those conducted with Cys 4 were then conducted in negative ESI mode with ProT $\alpha$, this nontraditional metal-binding peptide with coordination sites not involving redox active residues. Solutions of $20 \mu \mathrm{M}$ ProT $\alpha$ and a variety of molar equivalents of $\mathrm{Zn}^{2+}(0.1$ to 5.0$)$ were individually infused, and after only neutral aqueous washes, solutions of $20 \mu \mathrm{M}$ ProT $\alpha$ only were infused (spectra not shown). As in the Cys4 experiments, ProT $\alpha: \mathrm{Zn}^{2+}$ signal reappeared in the absence of $\mathrm{Zn}^{2+}$ in solution, and this occurred with the polarity continually set in the same mode (in this case, negative mode). If the only source of $\mathrm{Zn}^{2+}$ ions were redis- 
solved oxidized Zn, the ESI polarity would have to have been switched from negative to positive. This leads us to conclude that this phenomenon is independent of previously monitored redox processes. This is not to say that those redox processes could not concurrently occur under the proper conditions, just that the deposition happens either in addition to or altogether separate from the electrochemical process.

After determining that the stainless steel emitter retains zinc from peptide:zinc solutions during positive or negative ESI, and with two very different peptide sequences, a custom-built nanoESI interface using glass emitters was implemented, thus removing the stainless steel surfaces from the experiment. Then, a 1:1 Cys4: $\mathrm{Zn}^{2+}$ (10 $\mu \mathrm{M}$ each) solution was analyzed by nanoESI, and the results were compared with ESI-MS. Figure 4 shows a comparison of nanoESI and ESI spectra, where the different percentages of peptide bound to $\mathrm{Zn}^{2+}$ are seen to vary as a function of electrospray technique and flow rate. The mean ( \pm standard deviation) of the percent of Cys4 involved in zinc-binding was calculated to be $70 \%( \pm 3) \%$ for nanoESI (Figure $4 \mathrm{a})$, but drops to $48 \%( \pm 2) \%$ with ESI (Figure $4 \mathrm{~b}, 0.250 \mathrm{~mL} / \mathrm{h}$ infusion rate). When the ESI flow rate was increased dramatically to $2.00 \mathrm{~mL} / \mathrm{h}$, the nebulizer gas pressure was

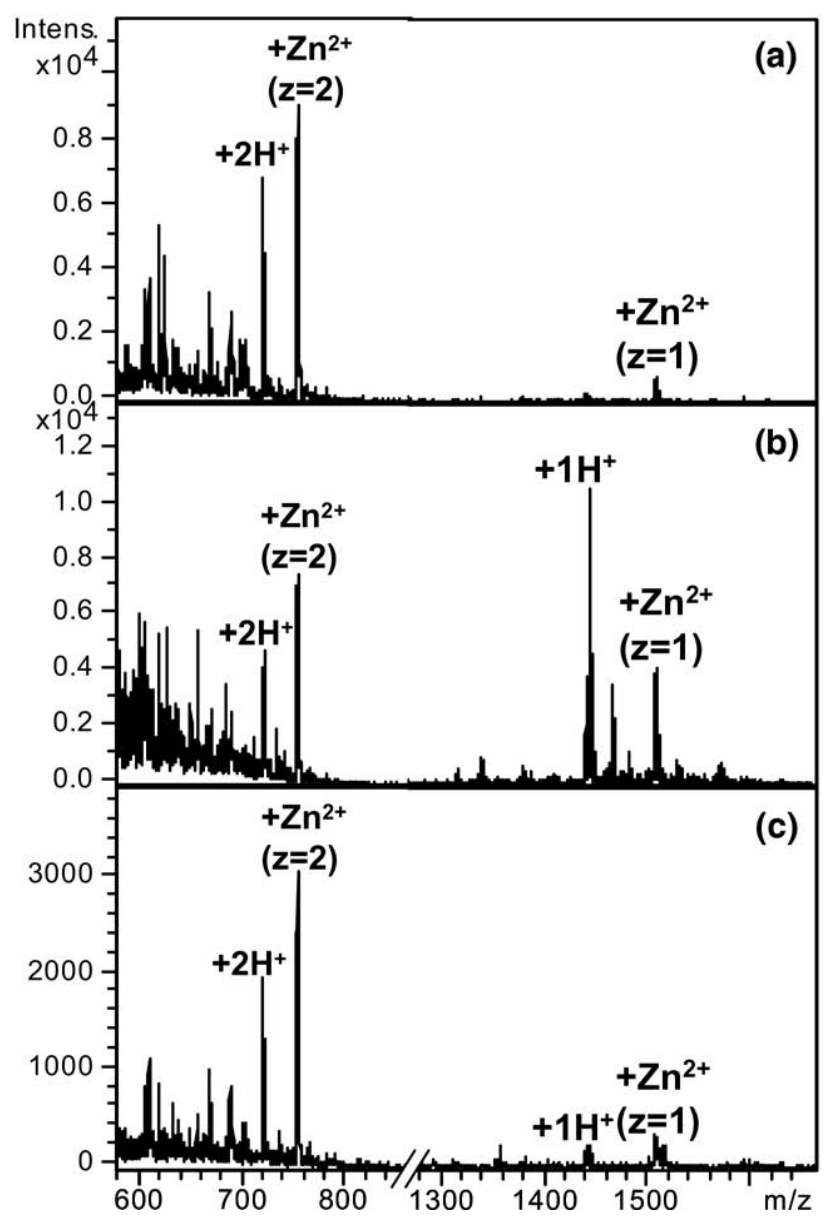

Figure 4. Mass spectra of 1:1 (10 $\mu \mathrm{M}$ each) Cys4: $\mathrm{Zn}^{2+}$ using (a) nanoESI, (b) ESI, $0.250 \mathrm{~mL} / \mathrm{h}$, and (c) ESI, $2.00 \mathrm{~mL} / \mathrm{h}$. doubled to $20 \mathrm{psi}$ and the position of the emitter plume was moved $\sim 2 \mathrm{~mm}$ away from the sampling aperture to accommodate the high volume entering the mass spectrometer. Under these conditions, the spectrum acquired in Figure 4c shows the percent of peptide signal due to the Cys4: $\mathrm{Zn}^{2+}$ complex increased to $71 \%( \pm 3) \%$, the same value observed with nanoESI. Using $\mathrm{K}_{\mathrm{d}}=8.0$ $\mathrm{pM}$ and working with $10 \mu \mathrm{M}$ solutions, one would expect $100 \%$ of the peptide to be in the metal-bound state. The nanoESI and the high-flow rate ESI data show a lower metal binding percentage than what the equilibrium calculations suggest, but the value is more in line with calculated predictions than what the slowflow rate ESI spectrum shows. Thus, these data provide evidence that changing the emitter material and altering the residence time of the solution in the stainless steel emitter strongly influence the resulting metal-peptide signal.

It should be emphasized that the relative comparison of signal intensities obtained from Figure 4 is valid only because the same Cys4: $\mathrm{Zn}^{2+}$ analyte solutions were used for both the nanoESI and ESI experiments, and it is the variation in signal intensities between the ESI and nanoESI data on which we are focused because of the observed retention of zinc in the ESI emitter. We can only use mass spectral intensities from the nanoESI source as evidence that less (or perhaps no) zinc is retained in the glass emitter versus the ESI stainless steel emitter. Our measurements of the absolute percent of peptide ions binding zinc ions are not expected to be accurate, partly because analyte solutions were not prepared with autotitrators, purchased metal salt standards, or under reducing conditions. However, it was important to choose a very strong zinc binding peptide (Cys4) so that detection of any free peptide in the mass spectrum would serve as a red flag that zinc was being lost during the analysis, regardless of whether the peak intensities could be used subsequently in a $\mathrm{K}_{\mathrm{d}}$ determination.

We can consider the different operating conditions used for ESI versus nanoESI as a possible cause for the different results obtained from the two techniques. The dry gas flow rate needed for ESI is five times higher than what is used in nanoESI, and no nebulizing gas is used in nanoESI. Typically, lower source temperatures can be used with the lower flow technique, as well. None of these parameter changes are expected to drastically affect the percentage of intact metal-peptide complex observed in the mass spectra. A thorough investigation of the effects of the mechanism of droplet formation and the gentleness of various ESI techniques on the $\mathrm{K}_{\mathrm{d}}$ determination experiments of various protein-ligand systems has been performed [25]. While the experiments did not involve metal-containing complexes, it is relevant that $\mathrm{K}_{\mathrm{d}}$ values for model non-metal systems were obtained with good agreement between ESI and nanoESI. For our work, where possible, control experiments were performed to confirm that the change in emitter material, and not other experimental con- 
ditions optimized differently for the two spray techniques, is the primary reason for the differences in ESI and nanoESI signal. For example, when using nanoESI as the ionization technique, the fraction of phytochelatin 4 (PC4) signal arising from PC4: $\mathrm{Zn}^{2+}$ complex was the same at $50{ }^{\circ} \mathrm{C}$ (vide infra) and at $250{ }^{\circ} \mathrm{C}$. Consequently, the generally regarded "gentleness" of the nanoESI source compared with the ESI source is not the key reason that higher signal intensity is observed from peptide ions with zinc bound to them. Instead, the emitter material appears to play the chief role.

The nanoESI-MS technique can even be used to complement the AAS data by providing a snapshot of how much zinc is deposited in the ESI stainless steel emitter. The nine amino acid PC4 was studied in positive mode. The phytochelatins, found in plants, are cysteine-rich peptides of varying lengths, which are capable of binding many different heavy metals [26]. For a $1: 1 \mathrm{PC} 4: \mathrm{Zn}^{2+}$ complex, the dissociation constant is between 0.5 and $0.9 \mu \mathrm{M}$ [27]. A $10 \mu \mathrm{M}$ PC4 solution with one equivalent of zinc added was analyzed with nanoESI, shown in Figure 5a. The average and standard deviation for the fraction of total peptide signal (eq 1) arising from the PC4: $\mathrm{Zn}^{2+}$ pair was $43 \%( \pm 2) \%$. Using the estimated dissociation constant of $0.7 \mu \mathrm{M}$ to calculate the fraction of peptide expected in the bound form, we arrive at the value of $77 \%$. As with Cys4, the measurement of only $43 \%$ PC4 in complex with $\mathrm{Zn}^{2+}$
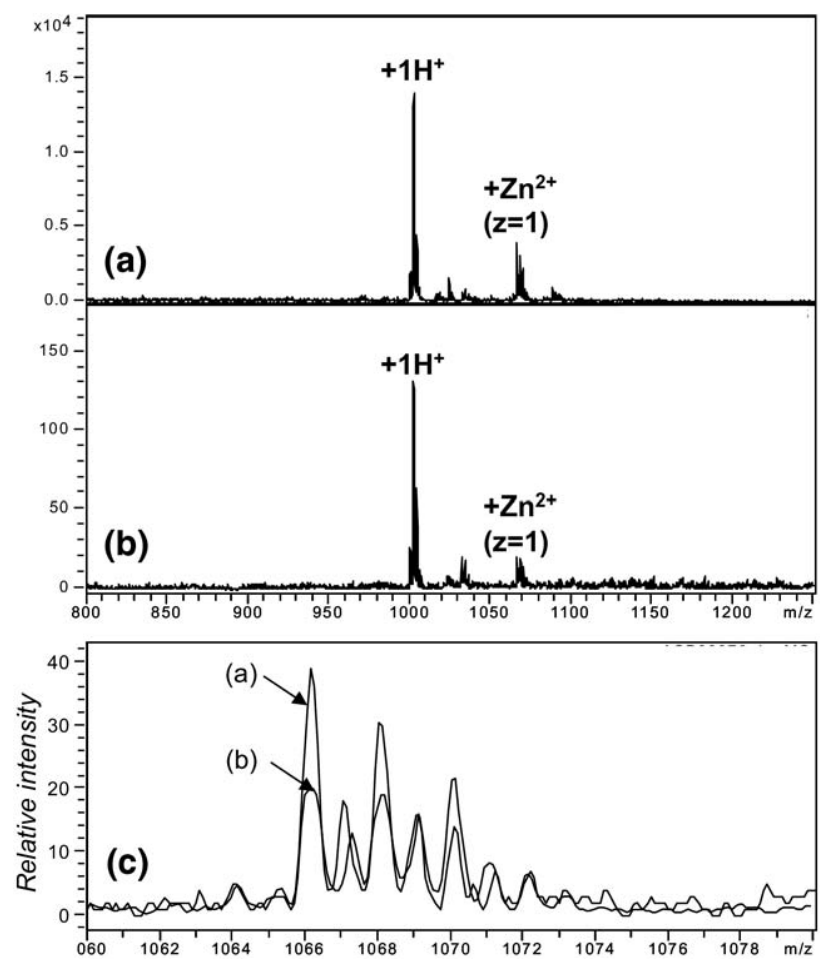

Figure 5. Mass spectra of 1:1 (10 $\mu \mathrm{M}$ each) PC4: $\mathrm{Zn}^{2+}$ using nanoESI (a) before infusion through the ESI emitter and (b) after infusion. A magnified view of the $+\mathrm{Zn}^{2+}$ peaks from (a) and (b) is shown in (c). using nanoESI is again lower than the expected value. But after infusion through the ESI emitter, the percent of peptide bound to zinc was even lower. A $0.250 \mathrm{~mL}$ aliquot of that same PC4: $\mathrm{Zn}^{2+}$ solution was infused through the ESI emitter at a flow rate of $0.250 \mathrm{~mL} / \mathrm{h}$ for $1 \mathrm{~h}$ with no ESI potential applied and no nebulizer or dry gas flowing. Sample was collected as described for the AAS experiments. This sample was then analyzed with nanoESI (Figure 5b), and the PC4: $\mathrm{Zn}^{2+}$ signal comprised only $17 \%( \pm 3) \%$ of the total peptide signal in the mass spectra. This represents approximately a $60 \%$ drop in zinc-related signal (Figure 5c), similar to the $50 \%$ drop in zinc concentration in the Cys $4: \mathrm{Zn}^{2+}$ solution after infusion at $0.250 \mathrm{~mL} / \mathrm{h}$ as measured by AAS. Because of the drop in zinc content of the analyte solutions after ESI infusion, ESI-MS peak intensities of these zinc-peptide complexes could not be reliably used in titration plots or other data analyses depicting the affinity of the peptide for the metal.

\section{Conclusions}

When peptide-zinc complexes were analyzed by ESI, zinc was deposited in the stainless steel emitter. This occurred regardless of ESI polarity, ruling out any compensating electrolytic deposition of the metal. It occurred for relatively strong zinc-binding peptides containing cysteine, a typical zinc binding amino acid, and for a weak zinc-binder that presumably binds through primarily electrostatic forces. At flow rates typical of conventional flow ESI, as much as $50 \%$ of the zinc present in the original sample is removed after infusion through the emitter assembly, before entering the mass spectrometer. As has been documented for electrolysis of analytes during ESI, slower flow rates altered the infused sample composition more dramatically [17]. Using a glass emitter in a nanoESI source yields a much higher zinc-peptide signal than seen with ESI. The observation of a low intensity zincpeptide signal in the nanoESI analysis of a sample that had been infused through the ESI emitter assembly reiterates that nanoESI is not simply gentler on the complex, but that the zinc was truly removed from the sample during the infusion step.

Knowing now that for zinc-peptide systems, nanoESI will yield more reliable results than the use of a stainless steel emitter in ESI, we will seek to reproduce previously determined $\mathrm{K}_{\mathrm{d}}$ values for zinc-peptide complexes falling in the nanomolar to micromolar range. This concentration range is above the limit of detection of nanoESI-MS, so competition experiments will not be necessary. Additionally, the deposition phenomenon may extend to other metals, making investigations of other metal-peptide systems crucial. There is also much to be learned about metal-binding behavior of phytochelatins that can be provided by mass spectrometry. For example, mass spectrometry has already been used to examine the stoichiometry of the PC4: $\mathrm{Zn}^{2+}$ complex when its electroinactivity rendered voltammetric stud- 
ies inconclusive [8]. We can exploit these systems to both investigate the metal deposition phenomenon and better describe the metal-binding characteristics of these phytochelatins.

\section{Acknowledgments}

The authors acknowledge support for this work by startup funds from East Carolina University (A.S.D.), American Chemical Society Petroleum Research Fund grant 41,395-GB4 (C.S.B.), and American Cancer Society Internal Research grant 5-66,171 (C.S.B.).

\section{References}

1. Gomez-Ariza, J. L.; Garcia-Barrera, T.; Lorenzo, F.; Bernal, V.; Villegas, M. J.; Oliveira, V. Use of Mass Spectrometry Techniques for the Characterization of Metal Bound to Proteins (Metallomics) in Biological Systems. Anal. Chim. Acta 2004, 524, 15-22.

2. Di Marco, V. B.; Bombi, G. G. Electrospray Mass Spectrometry (ESI-MS) in the Study of Metal-Ligand Solution Equilibria. Mass Spectrom. Rev. 2006, 25, 347-379.

3. Yen, T. Y.; Villa, J. A.; DeWitt, J. G. Analysis of Phytochelatin-Cadmium Complexes from Plant Tissue Culture Using Nano-Electrospray Ionization Tandem Mass Spectrometry and Capillary Liquid Chromatography/Electrospray Ionization Tandem Mass Spectrometry. J. Mass Spectrom. 1999, 34, 930-941.

4. Gehrig, P. M.; You, C.; Dallinger, R.; Gruber, C.; Brouwer, M.; Kagi, J. H. R.; Hunziker, P. E. Electrospray Ionization Mass Spectrometry of Zinc, Cadmium, and Copper Metallothioneins: Evidence for MetalBinding Cooperativity. Protein Sci. 2000, 9, 395-402.

5. Mineo, P.; Vitalini, D.; La Mendola, D.; Rizzarelli, E.; Scamporrino, E.; Vecchio, G. Electrospray Mass Spectrometric Studies of L-Carnosine (B-Alanyl-L-Histidine) Complexes with Copper(II) or Zinc Ions in Aqueous Solution. Rapid Commun. Mass Spectrom. 2002, 16, 722-729.

6. Zirah, S.; Rebuffat, S.; Kozin, S. A.; Debey, P.; Fournier, F.; Lesage, D.; Tabet, J.-C. Zinc Binding Properties of the Amyloid Fragment Ab(1-16) Studied by Electrospray-Ionization Mass Spectrometry. Int. J. Mass Spectrom. 2003, 228, 999-1016.

7. Wortmann, A.; Rossi, F.; Lelais, G.; Zenobi, R. Determination of Zinc to Beta-Peptide Binding Constants with Electrospray Ionization Mass Spectrometry. J. Mass Spectrom. 2005, 40, 777-784.

8. Chekmeneva, E.; Diaz-Cruz, J. M.; Arino, C.; Esteban, M. Binding of $\mathrm{Cd}^{2+}$ and $\mathrm{Zn}^{2+}$ with the Phytochelatin (g-Glu-Cys) ${ }_{4}$-Gly: A Voltammetric Study Assisted by Multivariate Curve Resolution and Electrospray Ionization Mass Spectrometry. Electroanalysis 2007, 19, 310-317.

9. Magyara, J. S.; Godwin, H. A. Spectropotentiometric Analysis of Metal Binding to Structural Zinc-Binding Sites: Accounting Quantitatively for pH and Metal Ion Buffering Effects. Anal. Biochem. 2003, 320, 39-54.

10. De la Mora, J. F.; Van Berkel, G. J.; Enke, C. G.; Cole, R. B.; MartinezSanchez, M.; Fenn, J. B. Electrochemical Processes in Electrospray Ionization Mass Spectrometry. J. Mass Spectrom. 2000, 35, 939-952.
11. Van Berkel, G. J. Electrolytic Deposition of Metals on to the HighVoltage Contact in an Electrospray Emitter: Implications for Gas-Phase Ion Formation. J. Mass Spectrom. 2000, 35, 773-783.

12. Johnson, K. A.; Shira, B. A.; Anderson, J. L.; Amster, I. J. Chemical and On-Line Electrochemical Reduction of Metalloproteins with HighResolution Electrospray Ionization Mass Spectrometry Detection. Anal. Chem. 2001, 73, 803-808.

13. Fenselau, C. Analysis of Metalloproteins by Electrospray Mass Spectrometry. Adv. Mass Spectrom. 2001, 15, 151-166.

14. Van Berkel, G. J.; Asano, K. G.; Kertesz, V. Enhanced Study and Control of Analyte Oxidation in Electrospray Using a Thin-Channel, Planar Electrode Emitter. Anal. Chem. 2002, 74, 5047-5056.

15. Wilson, C. L.; Monteith, W. B.; Danell, A. S.; Burns, C. S. Purification and Characterization of the Central Segment of Prothymosin- $\alpha$ : Methodology for Handling Highly Acidic Peptides. J. Peptide Sci. 2006, 12, 721-725.

16. Reddi, A. R.; Gibney, B. R. Role of Protons in the Thermodynamic Contribution of a $\mathrm{Zn}(\mathrm{II})-\mathrm{Cys}_{4}$ Site toward Metalloprotein Stability. Biochemistry 2007, 46, 3745-3758.

17. Van Berkel, G. J.; Zhou, F. Characterization of an Electrospray Ion Source as a Controlled-Current Electrolytic Cell. Anal. Chem. 1995, 67, $2916-2923$.

18. Van Berkel, G. J.; Giles, G. E.; Bullock, J. S., 4th; Gray, L. J. Computational Simulation of Redox Reactions within a Metal Electrospray Emitter. Anal. Chem. 1999, 71, 5288-5296.

19. Van Berkel, G. J. Insights into Analyte Electrolysis in an Electrospray Emitter from Chronopotentiometry Experiments and Mass Transport Calculations. J. Am. Soc. Mass Spectrom. 2000, 11, 951-960.

20. Kebarle, P. A Brief Overview of the Present Status of the Mechanisms Involved in Electrospray Mass Spectrometry. J. Mass Spectrom. 2000, 35, 804-817.

21. Blades, A. T.; Ikonomou, M. G.; Kebarle, P. Mechanism of Electrospray Mass Spectrometry: Electrospray as an Electrolysis Cell. Anal. Chem. 1991, 63, 2109-2114.

22. Henin, O.; Barbier, B.; Boillot, F.; Brack, A. Zinc-Induced Conformational Transitions of Acidic Peptides: Characterization by Circular Dichroism and Electrospray Mass Spectrometry. Chem. Eur. J. 1999, 5 , $218-226$.

23. Uversky, V. N.; Gillespie, J. R.; Millett, I. S.; Khodyakova, A. V.; Vasilendo, R. N.; Vasiliev, A. M.; Rodionov, I. L.; Kozlovskaya, G. D.; Dolgikh, D. A.; Fink, A. L.; Doniach, S.; Permyakov, E. A.; Abramov, V. M. $\mathrm{Zn}^{2+}$-Mediated Structure Formation and Compaction of the "Natively Unfolded" Human Prothymosin- $\alpha$. Biochem. Biophys. Res. Commun. 2000, 267, 663-668.

24. Monteith, W. B.; Wilson, C. L.; Burns, C. S.; Danell, A. S. Characterization of the Zinc-Binding Properties of Prothymosin- $\alpha$. Proceedings of the 54th ASMS Conference on Mass Spectrometry and Allied Topics; Seattle, WA, May 28-June 1, 2006.

25. Jecklin, M. C.; Touboul, D.; Bovet, C.; Wortmann, A.; Zenobi, R. Which Electrospray-Based Ionization Method Best Reflects Protein-Ligand Interactions Found in Solution? A Comparison of ESI, NanoESI, and ESSI for the Determination of Dissociation Constants with Mass Spectrometry. J. Am. Soc. Mass Spectrom. 2008, 19, 332-343.

26. Hirata, K.; Tsuji, N.; Miyamoto, K. Biosynthetic Regulation of Phytochelatins, Heavy Metal-Binding Peptides. J. Biosci. Bioeng. 2005, 100, 593-599.

27. Cheng, Y.; Yan, Y. B.; Liu, J. Spectroscopic Characterization of Metal Bound Phytochelatin Analogue (Glu-Cys) ${ }_{4}$-Gly. J. Inorg. Biochem. 2005, 99, 1952-1962. 